\title{
MULHERES QUILOMBOLAS E MEDICINA POPULAR: UM ESTUDO DE CASO EM SANTA RITA DE BARREIRA, PARÁ
}

\author{
Ana Célia Barbosa Guedes (1) $ه$
}

Hisakhana Corbin (D) $ه$

Universidade Federal do Pará I Belém - PA - Brasil 


\section{RESUMO}

Este artigo trata do uso da medicina popular entre as moradoras da comunidade quilombola de Santa Rita de Barreira, localizada no município de São Miguel do Guamá, no estado do Pará. Procurou-se entender a importância do uso terapêutico das plantas e as práticas de cura realizadas na comunidade. Além disso, mostrou-se que essas práticas, que refletem elementos das culturas indígenas e africanas, se perpetuam ao longo dos séculos. O estudo de caso foi realizado por meio de uma pesquisa de campo com algumas mulheres da comunidade, além de pesquisas bibliográficas.

Palavras-chave: mulheres; quilombo; práticas de cura.

\section{QUILOMBOLA WOMEN AND POPULAR MEDICINE: A CASE STUDY ON SANTA RITA DE BARREIRA, STATE OF PARÁ}

\section{ABSTRACT}

This paper focuses on the use of popular medicine among residents of the quilombola community of Santa Rita de Barreira, located in the municipality of São Miguel do Guamá, in the state of Pará. We sought to understand the importance of the therapeutic use of plants and the healing practices carried out in the community. In addition, we show that these practices, which reflect elements of indigenous and African cultures, have been perpetuated over the centuries. The paper is based on a case study in which qualitative data was collected from bibliographic sources. The case study was conducted with field research with some women from the community, in addition to bibliographic research.

\section{MUJERES QUILOMBOLAS Y MEDICINA POPULAR: UN ESTUDIO DE CASO EN SANTA RITA DE BARREIRA, PARÁ}

\section{RESUMEN}

Este artículo se centra en el uso de la medicina popular entre las habitantes de la comunidad quilombola de Santa Rita de Barreira. La comunidad está ubicada en el municipio de São Miguel do Guamá, en el estado de Pará, Brasil. Se busca comprender la importancia del uso terapéutico de las plantas y de las prácticas curativas llevadas a cabo en la comunidad. Además, se demostró que estas prácticas, que reflejan elementos de culturas indígenas y africanas, se han perpetuado a lo largo de los siglos. El estudio de caso se realizó mediante una investigación de campo con algunas mujeres de la comunidad, además de la recopilación de datos provenientes de fuentes bibliográficas. 


\section{INTRODUÇÃO}

No Brasil, desde o período colonial, a medicina popular vem sendo praticada por curadores(as) e benzedeiros(as), entre outros(as), para o tratamento e/ou a prevenção de doenças. Para tanto, as pessoas que recorrem a esse tipo de medicina utilizam algumas plantas existentes na região onde vivem (Oliveira 1985).

De acordo com Federici (2010), na Europa, durante a Idade Média e o início da Idade Moderna, as mulheres e os homens tratavam as doenças com plantas medicinais. Este conhecimento empírico em relação a plantas e remédios curativos foi adquirido ao longo dos anos, sendo transmitido por diversas gerações.

É importante destacar que, na sociedade brasileira, a medicina popular é o resultado das relações culturais entre portugueses, indígenas e africanos, após anos de contato e interação forçada, sendo difícil, hoje, distinguir quanto ao que é herança indígena, africana ou europeia. Restam, de concreto para análises, a curandeira, a benzedeira, entre outras, que poderão dar algo que indique, em parte, a origem étnica de suas técnicas empregadas (Araújo 1979). Nesse sentido, nas práticas de cura, as diversas medicinas populares se cruzam e espelham um mundo de saberes diferenciados (Oliveira 1985).

Até o século XIX, o uso de medicina popular era comum na sociedade brasileira, sobretudo entre os diversos grupos étnico-raciais e as classes sociais mais pobres. No entanto, a partir das últimas décadas desse século, as pessoas que continuavam utilizando aquelas práticas de cura passaram a ser alvo de perseguição por parte do Estado, pois, nesse período, a ideia de civilidade marcou os projetos de nação propostos para o país. Porém, a cultura dos povos indígenas e afro-brasileiros resistiu na região amazônica, com destaque para as práticas de cura popular (Rodrigues 2010).

Vale ressaltar que, até a contemporaneidade, os povos tradicionais habitantes da Amazônia brasileira usam a medicina popular para prevenção de doenças ou para curar os enfermos. Esses povos não a usam apenas, mas depositam credibilidade à medicina popular para tratar de várias enfermidades (Guedes 2018). Essas práticas se difundiram profundamente na sua construção cultural. Desse modo, os saberes relacionados ao cultivo e ao uso de plantas medicinais - com sementes, raízes, cascas, cipós, folhas e frutas para fazer chás, xaropes, garrafadas, lambedores e banhos - continuam fazendo parte da vida cultural e do cotidiano dos povos que vivem na comunidade quilombola de Santa Rita de Barreira.

Para os(as) moradores(as) desse quilombo, a floresta possui um significado muito importante, não só porque dela retiram os recursos para sua subsistência e prevenção ou para tratamento de doenças, mas 
também devido à sua ligação direta com a organização cultural e o modo de vida da comunidade.

Diante do exposto, o presente artigo busca mostrar os saberes das moradoras da comunidade quilombola de Santa Rita de Barreira relacionados ao uso e à manipulação de plantas medicinais para a prevenção e/ou o tratamento de doenças das pessoas que vivem nessa comunidade.

Este trabalho é parte da pesquisa de dissertação de mestrado de Ana Célia Guedes, defendida em 2018 pelo Programa de Pós-Graduação em Desenvolvimento Sustentável do Trópico Úmido
(PPGDSTU), Núcleo de Altos Estudos Amazônicos (NAEA), da Universidade Federal do Pará (UFPA).

\section{METODOLOGIA}

\subsection{APRESENTANDO A COMUNIDADE QUILOMBOLA}

O estudo foi desenvolvido na comunidade quilombola de Santa Rita de Barreira (Figura 1), localizada no km 12 da PA-251, na zona rural do município de São Miguel do Guamá, estado do Pará, com uma área total de 371 ha, perímetro de 18.379,51 $\mathrm{m}^{2}$ (Diniz 2011).

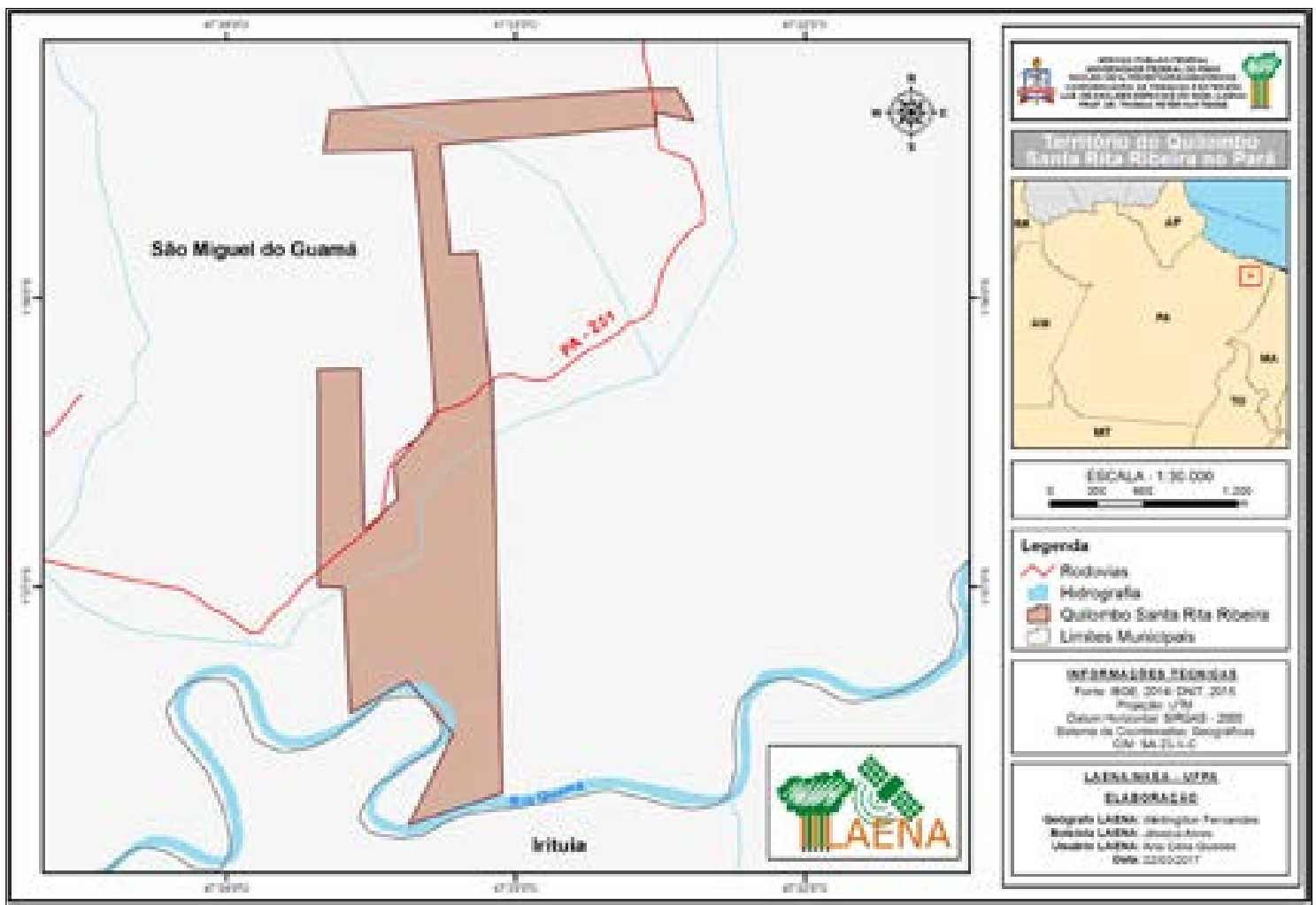

Figura 1 - Localização geográfica da comunidade quilombola de Santa Rita de Barreira. Mapa: Laboratório de Análises Espaciais do Núcleo de Altos Estudos Amazônicos (LAENA/NAEA-UFPA) (2017). 
Após várias lutas e mobilizações, em 2001, os(as) habitantes dessa comunidade quilombola deram início ao processo de demarcação e titulação do território, que tramitou alguns meses até que conseguissem o título de domínio coletivo e inalienável, entregue à comunidade em 22 de setembro de 2002. A titulação decorreu de acordo com a Lei Estadual n. 6.165, de 2 de dezembro de 1998 (Pará 1998), com o Decreto Estadual n. 3.572/1999 (Pará 1999) e a Instrução Normativa n. 02/1999.

A paisagem natural da referida comunidade não apresentava muitas alterações até o início do século $\mathrm{XX}$, pois os povos tradicionais que ali viviam retiravam da natureza apenas os recursos necessários à sua subsistência. Porém, a partir da segunda metade do século XX, o cenário daquele território sofreu várias transformações, sobretudo após alguns empresários da indústria ceramista se estabelecerem na região e começarem a extrair vários recursos naturais, como argila (matériaprima do tijolo e da telha), em larga escala, o que provocou grande impacto socioambiental no território quilombola (Diniz 2011).

Na comunidade, existe uma associação de moradores criada na década de 1990. É por meio dela que as pessoas que ali vivem se organizam politicamente para reivindicar do estado brasileiro políticas públicas de saúde, educação, moradia, entre outras necessidades. Durante a pesquisa de campo, realizada em 2017, o sr. Francisco Sá do Nascimento dos Santos, na ocasião presidente da associação de moradores(as), relatou-nos que havia cerca de 80 famílias na comunidade, cuja maioria possui relações de parentesco.

O território da comunidade quilombola apresenta um povoado com várias construções antigas e outras novas, com quintais bastante arborizados (Figura 2); possui um campo de futebol, que serve de diversão para homens e mulheres locais; uma igreja católica; uma escola, que funciona apenas atendendo alunos(as) do ensino fundamental I; e um centro comunitário, local em que as pessoas também se reúnem para discutir os problemas e as soluções referentes à garantias de acesso às demandas políticas e sociais locais (Guedes 2018).

Nos quintais, são cultivadas plantas ornamentais, medicinais, frutíferas e não frutíferas. Estas últimas são hortadas com a finalidade de tornar o espaço mais arejado. Geralmente, as plantas medicinais são cultivadas nos espaços atrás das casas, em locais suspensos ou no chão, e são protegidas de ataque de animais por cercas feitas de madeira.

\subsection{COLETA DE DADOS}

Considerando que há poucos registros escritos sobre a comunidade quilombola de Santa Rita de 


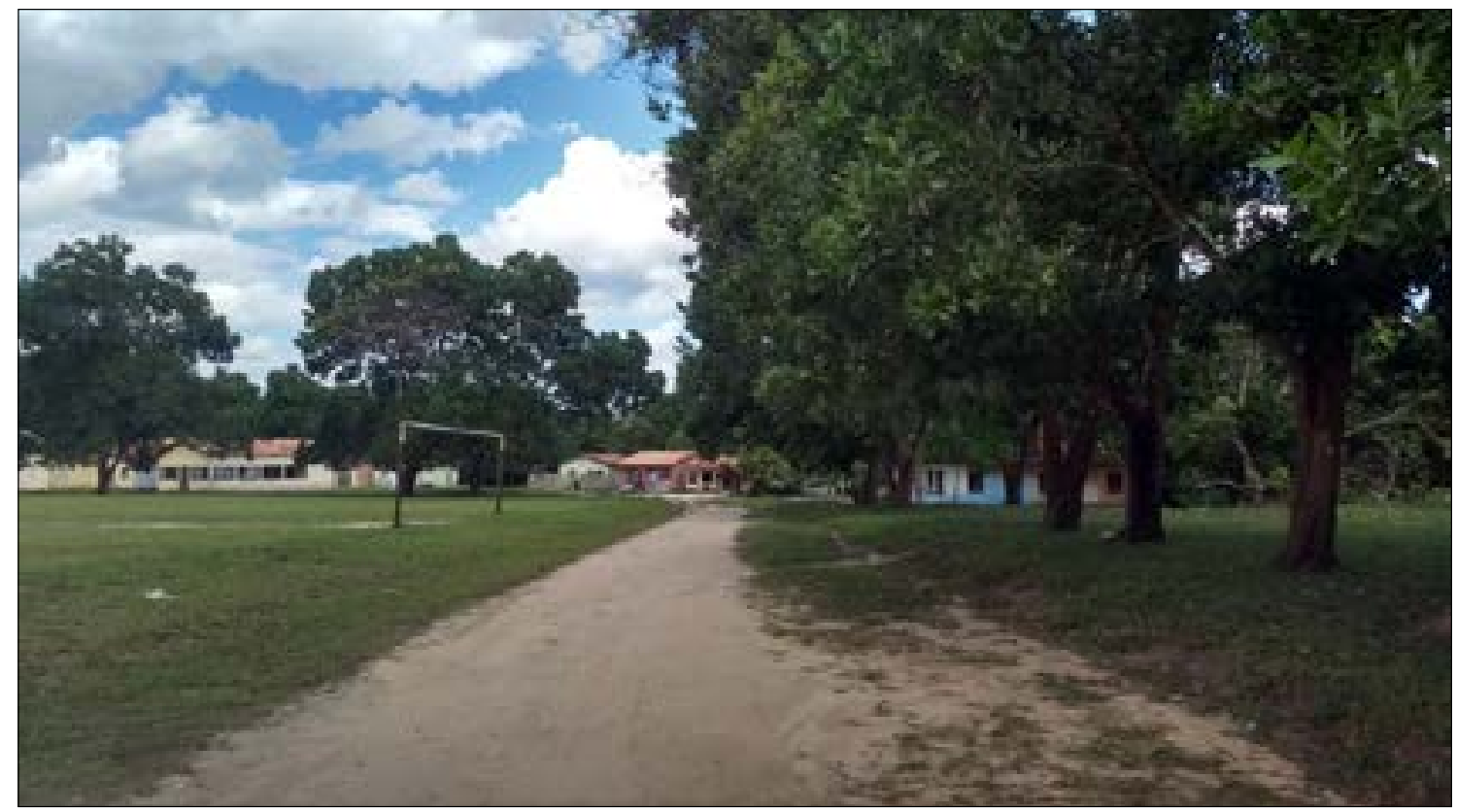

Figura 2 - Entrada da comunidade quilombola de Santa Rita de Barreira. Foto: Ana Célia Guedes (2017).

Barreira, especialmente acerca do uso da medicina popular e dos saberes relacionados ao cultivo e à manipulação de plantas medicinais para prevenção/ tratamento de algumas doenças que assolam as pessoas nessa localidade, utilizamos prioritariamente como metodologia de pesquisa a revisão bibliográfica sobre a temática e a história oral, para estabelecer e ordenar todo o procedimento do trabalho.

Para Alberti (2010), a história oral pode ser usada como fonte para análise e compreensão da história contemporânea, já que é um procedimento investigativo constituído de entrevistas com indivíduos que viveram/vivem ou testemunharam/ testemunham fatos do passado ou do presente. Ela é também um caminho para analisar e compreender o cotidiano, o trabalho, as festas, os rituais e as tradições de grupos sociais que não possuem documentos escritos (Alberti 2010).

De acordo com Portelli (2016:10), a “[...] história oral, então, é primordialmente uma arte da escuta", pois ela é gerada durante a entrevista, na qual pergunta e resposta não seguem necessariamente as mesmas direções. Nesse sentido, ela pode gerar novas histórias e estas, por sua vez, colaboram para dar voz às experiências vividas por grupos ou sociedades que foram excluídos de narrativas escritas oficiais. Portanto, trata-se de mais um meio de informações que o(a) pesquisador(a) dispõe para a construção da percepção, no tempo e no espaço da existência humana (Lozano 2006).

Assim, para compreender a importância da medicina popular e dos saberes tradicionais 
existentes no quilombo de Santa Rita de Barreira, foi necessário entrevistar várias pessoas de diferentes faixas etárias, em especial, as mulheres, pois são elas as responsáveis pelo cultivo e pela manipulação das plantas medicinais, bem como por transmitirem, de geração a geração, os saberes relacionados a isso.

Para os(as) moradores(as) da comunidade, medicina popular são as estratégias que as pessoas mais velhas buscaram para tratar as doenças que assolam os(as) parentes, amigos(as) e vizinhos(as) a partir do uso dos recursos naturais existentes no território quilombola ou em outros territórios. Estas estratégias são vistas pela maioria das pessoas da comunidade como saberes tradicionais importantes, os quais são transmitidos pela oralidade ao longo do tempo.

Para tanto, não foi realizada uma amostragem aleatória ou seleção de um grande número de participantes ${ }^{1}$, pois não se trata de uma amostra probabilista, mas sim por propósito, visto que, neste tipo de procedimento, os(as) investigadores(as) podem coletar formas múltiplas de dados e gastam bastante tempo no local da pesquisa, reunindo informações que são importantes para a compreensão do cotidiano de um determinado grupo social (Creswell 2007).

Dessa forma, optou-se por entrevistar 12 (doze) mulheres que moram na comunidade, com diferentes faixas etárias, especificamente entre 20 e 89 anos, selecionadas de acordo com o acesso e a disponibilidade, pois nem sempre as encontrávamos, visto que geralmente estão realizando alguma atividade, seja em casa ou nas roças. Neste artigo, foram utilizados os nomes reais das entrevistadas, autorizado por elas. Realizadas entre os meses de junho a agosto de 2017, as entrevistas contribuíram para compreensão da história do grupo social e do uso de medicina popular entre as moradoras da comunidade.

A pesquisa de campo foi feita a partir da observação participante. Nesse procedimento, a pesquisadora esteve aberta a uma maior amplitude e profundidade de informações e, ao mesmo tempo, foi possível notar diferentes impressões e observações, que conferiram discrepâncias no decorrer do trabalho (Gaskell 2008).

Optou-se pela aplicação de perguntas semiestruturadas, pois questões muito fechadas não revelam aspectos importantes sobre o modo de vida das entrevistadas. Essa estratégia fez com que elas ficassem mais à vontade e estabelecessem

1 A pesquisa adotou procedimentos éticos em relação aos(às) sujeitos(as) participantes, levando em consideração a necessidade de obtenção do consentimento das pessoas que fizeram parte do estudo, bem como sua participação voluntária. Assim, foi assinado pelo presidente da associação e pelos(as) moradores(as) da comunidade que participaram da pesquisa um Termo de Consentimento Livre e Esclarecido (TCLE), no qual havia a solicitação formal de autorização para a realização da pesquisa. 
uma relação de confiança e segurança com a entrevistadora, possibilitando que assuntos importantes à pesquisa fossem registrados nessa etapa (Gaskell 2008).

A pesquisa foi de caráter qualitativo, visto que este método contribui para mapear e compreender o mundo de alguns grupos humanos, e é o ponto de entrada para cientistas sociais que introduzem esquemas interpretativos para a compreensão de narrativas, crenças, atitudes e valores de grupos sociais em termos mais conceituais e abstratos (Gaskell 2008).

Foi realizado um estudo de caso sobre o uso de medicina popular praticado na comunidade, pois procuramos compreender os fenômenos e comportamentos individuais e coletivos relacionados ao uso e à manipulação de plantas medicinais para o tratamento de algumas doenças. Essa modalidade de pesquisa contribuiu para compreensão das relações históricas, socioculturais e políticas do grupo racial investigado, além de possibilitar um estudo profundo de um grupo social (Gil 1999). Conforme Yin (2010), o estudo de caso fornece elementos para entender os fenômenos individuais, de grupos e organizações, bem como permite a compreensão dos fenômenos em profundidade na sua totalidade, por exemplo, ciclos individuais de vida e comportamento de pequenos grupos sociais.

\section{MEDICINA POPULAR E SABERES LOCAIS: PRÁTICAS DE CURA EM SANTA RITA DE BARREIRA}

Os povos que viviam na Amazônia antes da chegada do colonizador europeu usavam recursos naturais existentes na floresta para tratar suas enfermidades. A colonização portuguesa do território não alterou essas práticas de cura e, ao contrário, as intensificou, pois muitos povos africanos que chegaram nessa região entraram em contato com várias etnias indígenas. Desse modo, os conhecimentos dos africanos sobre plantas medicinais acabaram interagindo com os saberes dos indígenas (Guedes 2018).

Vale destacar que os povos africanos que chegavam à América trouxeram vários conhecimentos, entre eles o uso terapêutico de plantas, pois fazia parte da cultura de diversas nações africanas (Silva et al. 2012). Assim, na contemporaneidade, tais saberes ainda estão presentes no cotidiano e nas práticas das mulheres pertencentes a comunidades quilombolas, como a de Santa Rita de Barreira. São elas que realizam os cuidados de saúde, tratam as enfermidades de seus familiares, vizinhos e amigos, a partir de seu conhecimento quanto ao preparo de plantas medicinais existentes nos canteiros e na floresta. A procura pela medicina oficial ou por médicos para tratar os enfermos raramente ocorre, porque 
acreditam nos benefícios dos remédios feitos à base de plantas, e também porque estes remédios funcionam. Além disso, esta prática /faz parte do sistema local de cuidados com a saúde.

É importante frisar que, nesse território, não existe posto de saúde e grande parte das pessoas com mais de 30 anos de idade procurou apenas uma ou duas vezes assistência médica para tratar algum tipo de enfermidade ao longo de sua vida. Os(as) moradores(as) locais informaram que apenas recorreram à medicina médica nos casos em que a doença não podia ser tratada com a curandeira da comunidade, pois nos casos de cirurgia, por exemplo, ela os(as) recomenda a irem procurar um hospital (Guedes 2018). Além disso, para conseguir acesso a uma consulta médica, as pessoas que ali vivem precisam se deslocar até a sede do município e, muitas vezes quando chegam ao hospital municipal, não conseguem atendimento. $\mathrm{O}$ acesso à sede do município ocorre geralmente por via rodoviária e leva em média 45 a 60 minutos de carro. A viagem é relativamente rápida, porém, as pessoas da comunidade, em sua maioria, não possuem carro e o transporte coletivo passa apenas uma vez ao dia.

A ausência e/ou precariedade de intervenção do Estado brasileiro em várias regiões persiste até o século XXI e contribui para a falta de implementação de políticas públicas de saúde na maioria das comunidades quilombolas existentes na região amazônica, mesmo com avanços em acesso à ciência e à tecnologia no país (Guedes 2018). No entanto, ainda que fossem implantadas as políticas de saúde do Estado na comunidade, a medicina popular não deixaria de ser realizada, pois as práticas terapêuticas de saúde a partir do uso de plantas medicinais permanecem enquanto um saber tradicional e continuam sendo transmitidas. Assim, muitas pessoas que vivem na região, mesmo tendo acesso a tratamentos médicos, permanecem usando remédios à base de plantas medicinais, outras usam as duas medicinas simultaneamente, como destacou dona Ana Lúcia:

[...] quando eu tô ruim eu vou lá na minha comadre, a dona Antônia Almeida [...] eu vou lá, ela me ensina uns remédio e aí vou e tomo, olha, um tempo desse eu tava com uma dor aqui nas costas [...], aí meu filho veio aqui e perguntou se eu queria ir pro hospital ou na casa da tia Antônia, porque ele pergunta logo, aí eu disse: eu acho que vou primeiro na comadre Antônia. Aí, chegando lá se for pra ir pro hospital ela vai dizer pra mim [...] Aí eu fui lá e ela puxou e disse, olha, comadre, não é rasgadura. Aí, ela disse: olhe, eu vou lhe passar esse chá aqui, é vento empossado, eu vou lhe passar esse chá [...]. O chá era a folha do favacão, era cravinho, erva doce, era a folha do cordão de São Francisco, era a folha de elixir paregórico, era a folha do alho [...] não sinto mais nada, eu tomei os cinco, né? Que ela tinha ensinado cinco, tomei todos cinco chá, aí não precisou mais eu ir no hospital (Ana Lúcia Braga Santos, 47 anos, Santa Rita de Barreira, comunicação pessoal, jul. 2017). 
Dona Maria Rosilene Xavier Gomes também nos contou um pouco de sua experiência:

\begin{abstract}
A gente não leva pro hospital porque lá a gente não pode fazer nada, e não vão dá o remédio certo, agora presta atenção [...] se você for na minha madrinha agora com uma dor de cabeça, ela já lhe ensina o remédio, lá no médico você vem com exame, daqui um mês, quinze dias você não pode aguentar, não vai aguentar porque são pessoas que the olha assim [...] olha, eu vou lhe dizer quando tô com dor de cabeça vou logo na minha madrinha que ela me diz "faz um chá da folha de chicória e bebe várias vezes", e eu faço e logo fico boa [...] (Maria Rosilene Xavier Gomes, 38 anos, Santa Rita de Barreira, comunicação pessoal, 2017).
\end{abstract}

Os relatos de dona Ana Lúcia e de dona Maria Rosilene revelam que as pessoas da comunidade buscam prioritariamente tratar suas enfermidades com plantas medicinais e somente se não obtiverem resultados positivos procuram os hospitais da região. Nesse sentido, os povos negros e indígenas criaram e recriaram várias estratégias de sobrevivência e formas de assistências autônomas adequadas aos contornos específicos da região amazônica, além de outros modos de vida fora dos parâmetros de bem-estar propostos pela modernidade ocidental, eurocêntrica e capitalista, pois aquele modo de vida está relacionado com o uso da biodiversidade para fins medicinais, bem como fortalece ações voltadas aos povos e às comunidades tradicionais sobre os direitos territoriais, a integração, as tradições e a manutenção da cultura.

Dona Maria Hosana, moradora da comunidade, também nos relatou a importância das práticas terapêuticas a partir do uso de plantas medicinais:

[...] olha, sendo que se eu cismar que meus filho tão com problema de verme eu vou, eu pego a flor do mamão macho [...] Aí, eu pego o alho e a flor do cajueiro [...] aí, eu vou, pego, faço chá e dou. Aí, se não resolver, aí eu faço o chá da raiz da chicória que ela é boa também, sendo que se for coisa no intestino, né? Empachamento, eu pego sempre o alho, a casca da laranja, que é boa também, e o elixir paregórico em planta e faço o chá e dá certo [...] só se for um caso muito grave pra eu ir pro médico, eu sempre gostei de fazer chá pros meus filho (Maria Hosana dos Santos Castro, 46 anos, Santa Rita de Barreira, comunicação pessoal, 2017).

Essas mulheres conhecem muito bem as plantas que servem para tratar determinadas enfermidades e as distinguem pelo tamanho das folhas, pelo cheiro etc., além de saberem como devem ser utilizadas. Desse modo, confiam nessas plantas e em seus conhecimentos para tratar as enfermidades que assolam as pessoas da família ou do grupo no qual estão inseridas.

Assim, a maioria das habitantes da comunidade, desde criança, utiliza medicamento feito à base de plantas medicinais e lembra de suas mães ou avós fazendo chás para beberem quando estavam com algum sintoma de doenças, como febre, dor de barriga, entre outras. Dessa forma, nessa 
comunidade quilombola, assim como na maior parte dos povoados negros da Amazônia Legal, esta prática está relacionada ao conhecimento advindo da base familiar. Assim, não existe uma única maneira norteadora que oriente todas as pessoas e classes sociais a criarem suas estratégias de vida e, entre estas, estão as práticas de cura (Oliveira 1985).

Nesse sentido, a medicina popular é uma prática familiar compartilhada na comunidade quilombola, entre parentes, amigos e vizinhos que possuem a mesma visão de mundo, o que proporciona respostas concretas aos problemas de doenças e sofrimentos vividos no cotidiano de um determinado grupo social. Ela acaba aproximando e fortalecendo as relações sociais entre os sujeitos, pois implica ajuda e solidariedade entre eles (Oliveira 1985).

A medicina popular produz estratégias de tratamento de doenças muito peculiares. Ela se dá por prevenção, diagnóstico e tratamento de enfermidades, sendo inserida dentro da cosmovisão de cada povo e, constantemente, é recriada e reinventada, de acordo com o contexto histórico de cada grupo social (Oliveira 1985). Esse tipo de medicina é uma prática de cura concreta, não sendo apenas uma questão de acreditar, e nos mostra que, no campo da saúde, não existe uma única maneira de fazer ciência (Oliveira 1985).
De acordo com Lévi-Strauss (1989), povos como os indígenas eram conhecedores de vários tipos de plantas, muitas delas com propriedades narcóticas, estimulantes ou medicinais, e também conheciam muito bem o meio biológico. LéviStrauss (1989) denomina o conhecimento empírico de "ciência do concreto", pois, embora seja por essência restrito, se comparado aos resultados das ciências exatas e naturais, ele não foi menos científico e seus resultados não foram menos reais. $\mathrm{O}$ interesse desses povos não se restringia às plantas comestíveis ou às que serviam como medicamento, uma vez que as espécies animais e vegetais não são conhecidas porque são benéficas, elas só são consideradas benéficas ou importantes porque são primeiramente conhecidas (LéviStrauss 1989).

Assim, mulheres como as de Santa Rita de Barreira usam a medicina popular em suas práticas de cura cotidianamente e, a partir de seus relatos e da observação empírica, foi possível depreender que elas possuem conhecimento relacionado à prática de cura a partir de uso de plantas medicinais, além de conhecerem os benefícios e saberem preparar chás e banhos.

Durante a pesquisa de campo, dona Socorro (38 anos), moradora da comunidade, relatou-nos que o chá da flor da alfavaca (Ocimum basilicum) é recomendado para o combate de dores no estômago 
e sempre que algum parente ou vizinho está com esse problema ela faz o chá para eles. Após algumas horas, os sintomas da doença desaparecem. Ela nos informou também que usa algumas raízes, caule e folhas de várias plantas existentes na região para fazer chás e banhos, algumas servem para prevenção e outras ao tratamento de doenças.

Maria Giele Xavier (moradora da comunidade e, no período da pesquisa, com 20 anos de idade) nos relatou que toma o chá da folha de hortelã (Mentha villosa) e do elixir paregórico (Piper callosum) quando está com dores abdominais. A jovem aprendeu a fazer o chá com uma curandeira da comunidade, o que significa que essas mulheres se preocupam em transmitir os conhecimentos relacionados ao uso terapêutico de plantas aos mais jovens, pois sabem dos benefícios e da importância dos remédios à base de plantas para o bem-estar de seu grupo social.

Segundo as moradoras da comunidade quilombola, a maioria das pessoas que ali vive usa plantas como oriza (Pogostemon cablin) (Figura 3), entre outras, para fazer banhos e espantar mauolhado, já que, para elas, esse é um problema que afeta as relações sociais e econômicas. Por isso, ensinam seus/suas filhos(as) e vizinhos(as) sobre como devem fazer os banhos para solucionar esses problemas.

De acordo com Araújo (1979), o banho é um ritual curativo, não um ato de limpeza. Ele funciona como remédio, por isso colocam-se nele folhas, raízes etc., com o objetivo de limpar o corpo dos possíveis males que afetam o paciente.

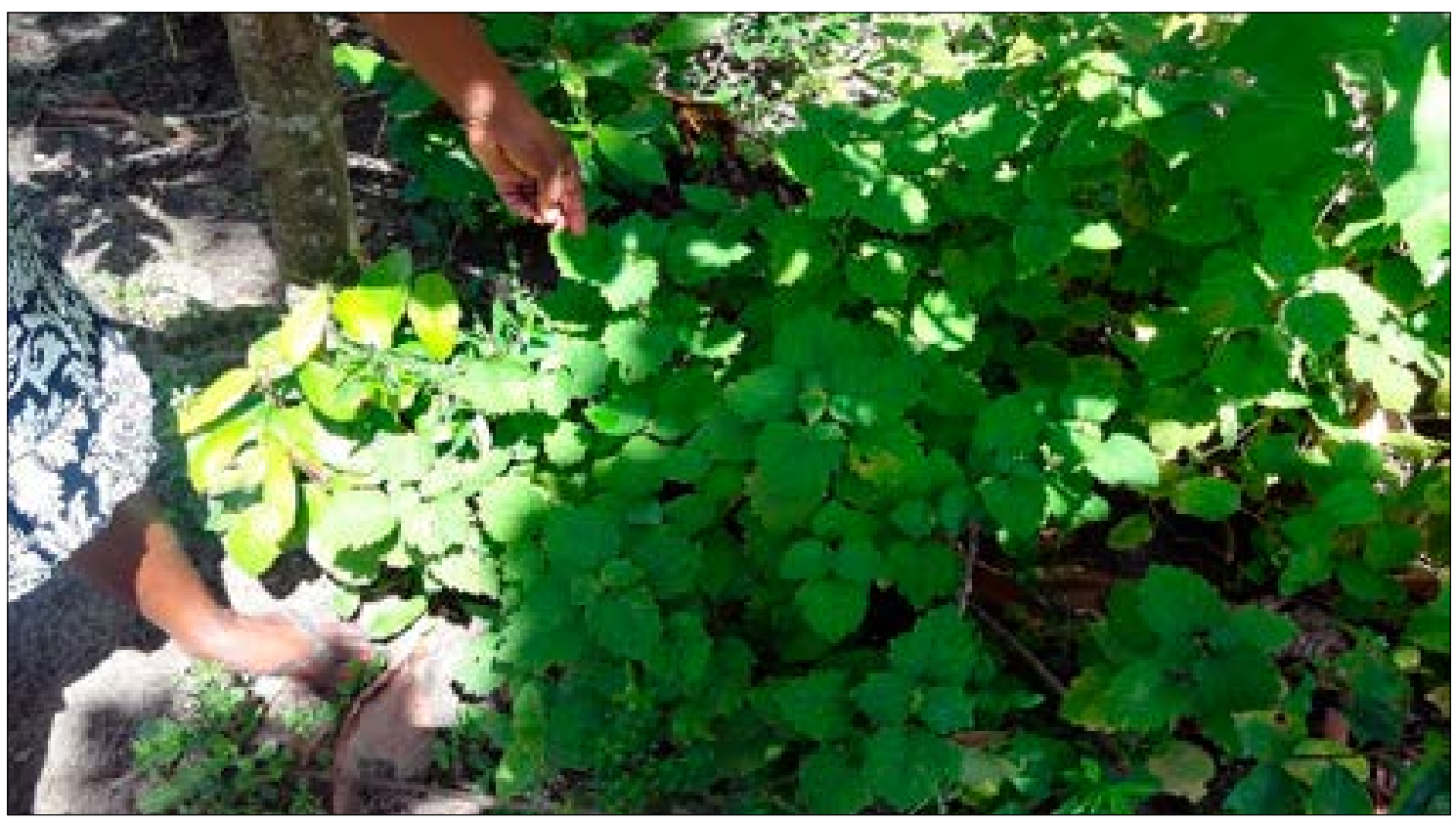

Figura 3 - Oriza (Pogostemon cablin). Foto: Ana Célia Guedes (2017). 
Desse modo, é comum entre as pessoas que vivem na comunidade quilombola o uso de vários tipos de plantas que servem para diferentes problemas, a exemplo da unha-de-gato (Uncaria tomentosa), que possui propriedades analgésicas, anti-inflamatórias, antioxidantes, entre outras. Ela possui, ainda, substâncias medicinais importantes à saúde humana que foram descobertas pelos povos tradicionais a partir do conhecimento empírico e da necessidade de sobrevivência na floresta (Guedes 2018).

É importante ressaltar que as mulheres da comunidade não conhecem apenas as plantas que utilizam para fins medicinais, mas também as prejudiciais à saúde. Elas desconhecem o nome científico e as substâncias químicas das plantas, porém sabem as que servem para prevenir ou tratar enfermidades e a quantidade necessária para fazer os remédios. Nesse sentido, para essas mulheres, o valor farmacológico das plantas medicinais não está em primeiro plano, e sim os benefícios que elas podem trazer na prevenção e no tratamento de algumas enfermidades, por isso buscam conhecêlas e depois utilizá-las em forma de garrafadas, xaropes, chás e banhos.

Assim, é possível afirmar que as mulheres da comunidade são herdeiras de uma longa tradição científica, não do conhecimento científico moderno, pois aquela se diferencia deste em vários aspectos, entre eles, no que diz respeito às estratégias de se relacionar com a natureza. Isso porque as mulheres que ali vivem sabem da importância da biodiversidade existente na região e procuram conhecê-la e conservá-la, cultivando plantas em seus quintais ou não permitindo a derrubada da floresta (Guedes 2018).

É importante reconhecer os saberes relacionados à manipulação de plantas medicinais enquanto construção e reconstrução do processo histórico e sociocultural do cuidar cotidiano e como expressões culturais, mas também como estratégias dos modos de vida de vários povos tradicionais que vivem tanto na Amazônia brasileira quanto na Pan-Amazônia (Freire 2008). Esse modo de vida, em muitos aspectos, contrapõe-se ao modelo hegemônico imposto pelo Estado brasileiro.

\section{AS PLANTAS MEDICINAIS DOS QUINTAIS E DA MATA}

Muitos povos que vivem na Amazônia possuem vasto conhecimento sobre o uso e manejo das plantas nos quintais, desenvolvendo técnicas de cultivo que garantem o equilíbrio ecológico dos recursos naturais (Coelho-Ferreira \& Jardim 2005). Para Winklerprins \& Oliveira (2010), esses espaços envolvem um intercâmbio de material genético que atrela a diversidade existente nos ecossistemas naturais às culturas ou às tradições das comunidades humanas locais. 
Na comunidade quilombola de Santa Rita de Barreira não é diferente, pois a maioria das plantas medicinais utilizadas pelas pessoas são cultivadas nos quintais e outras são coletadas na floresta, como informou dona Maria Dejanira Xavier (42 anos):

\begin{abstract}
[...] é, a gente que cuida dessas plantas pra não morrer quando é verão, tem que tá molhando, aí, às vez, quando a gente vê que já tá tempo, aí a gente pega, faz outra muda. [...] Algumas plantas a gente pega mais no mato, é a verônica, é barbatimão, unha-degato, é porque essas plantas assim são mais da natureza, [...] por isso ninguém derruba lá perto dela porque a gente não pode ficar sem nada, sem elas, aí elas fica lá mesmo (Maria Dejanira Xavier, 42 anos, Santa Rita de Barreira, comunicação pessoal, 2017).
\end{abstract}

Dona Socorro, moradora da comunidade, relatou-nos que procura cultivar em seu quintal várias espécies de plantas: “[...] Temos nossas plantas do terreiro, a chicória, alfavaca, eu que planto, taí no meu terreiro de prova, planto mastruz, hortelã, planto muitas coisas, pode olhar meu terreiro [...]" (Socorro, 38 anos, Santa Rita de Barreira, comunicação pessoal, 2017).

A partir dos relatos de dona Maria Dejanira Xavier e de dona Socorro, ambas moradoras da comunidade, observa-se o quanto as pessoas que ali vivem conhecem a biodiversidade existente na região e possuem a preocupação de cultivar em seus quintais várias plantas, como gengibre (Zingiber officinale), jambu (Acmella oleracea), laranjeira (Citrus $x$ sinensis), elixir paregórico (Piper callosum), entre outras, bem como conservar as existentes na floresta, como unha-de-gato (Uncaria tomentosa), verônica (Veronica officinalis), entre outras. Desse modo, elas se preocupam em deixar a floresta em pé porque sabem da importância da conservação das espécies e da sociobiodiversidade. Por isso, é comum nos quintais das casas das moradoras dessa comunidade o cultivo de várias plantas medicinais (Figura 4 e 5).

Os quintais amazônicos são unidades produtivas manejadas durante anos que fornecem meios de subsistência às comunidades urbanas e rurais (Trotta et al. 2012), indispensáveis para seleção, cuidado e proteção de plantas alimentares, ornamentais, mágicas e medicinais (Eichemberg et al. 2009).

A observação empírica revelou que as plantas cultivadas nos quintais para uso medicinal são geralmente de pequeno porte, como mastruz (Dysphania ambrosioides), hortelã da folha miúda (Mentha villosa), entre outras. As de grande porte, como barbatimão (Stryphnodendron) e unha-degato (Uncaria tomentosa), são retiradas da floresta, geralmente, em lugares próximos aos igapós.

A maior parte das mulheres da comunidade reconhece dezenas de espécies de plantas (Tabela 1). O conhecimento relacionado ao cultivo, ao uso e à manipulação de plantas medicinais é transmitido por meio da oralidade por várias gerações e são, principalmente, as mulheres as responsáveis por 


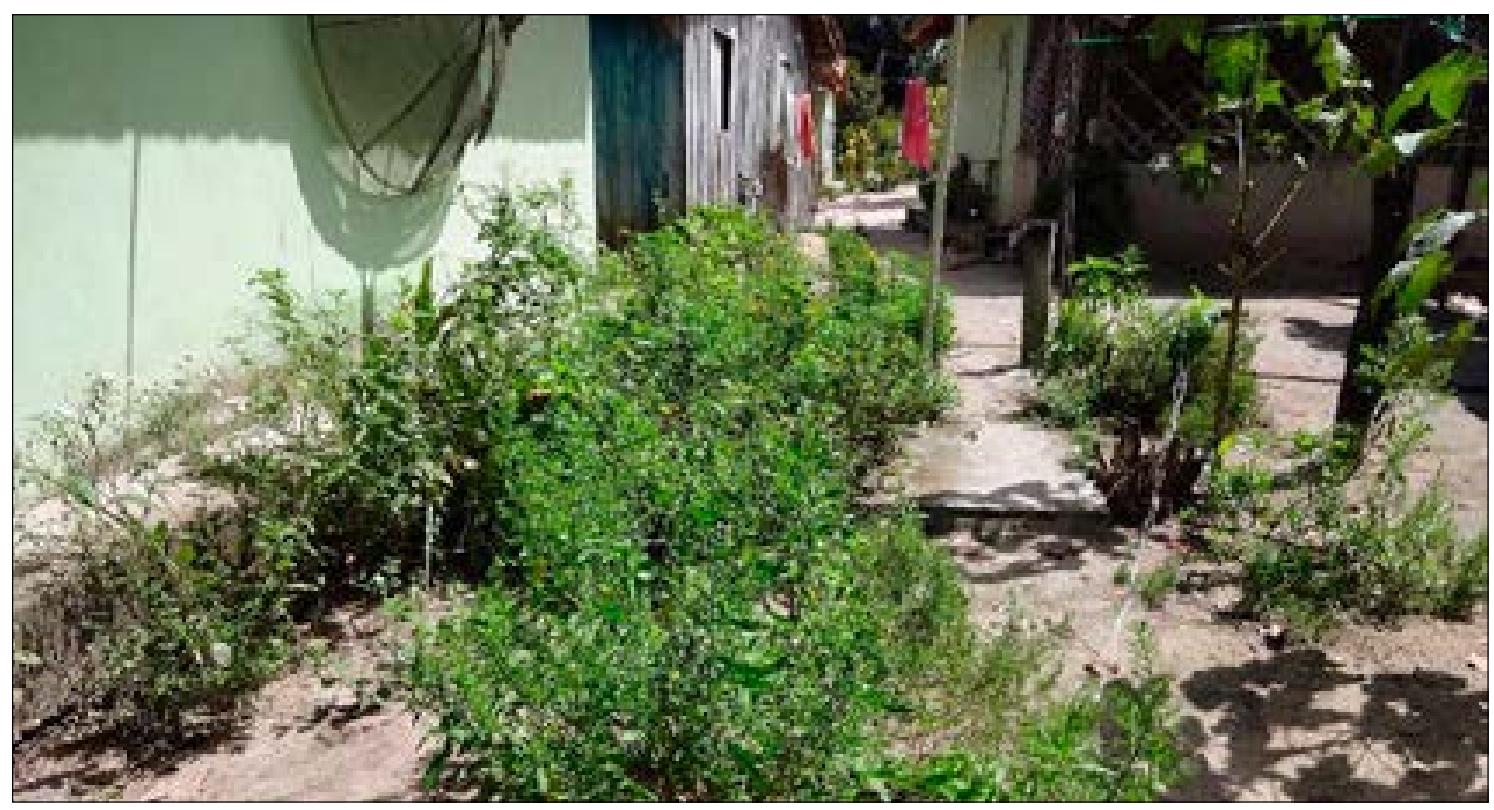

Figura 4 - Quintal de dona Maria Dejanira Xavier. Foto: Ana Célia Guedes (2017).

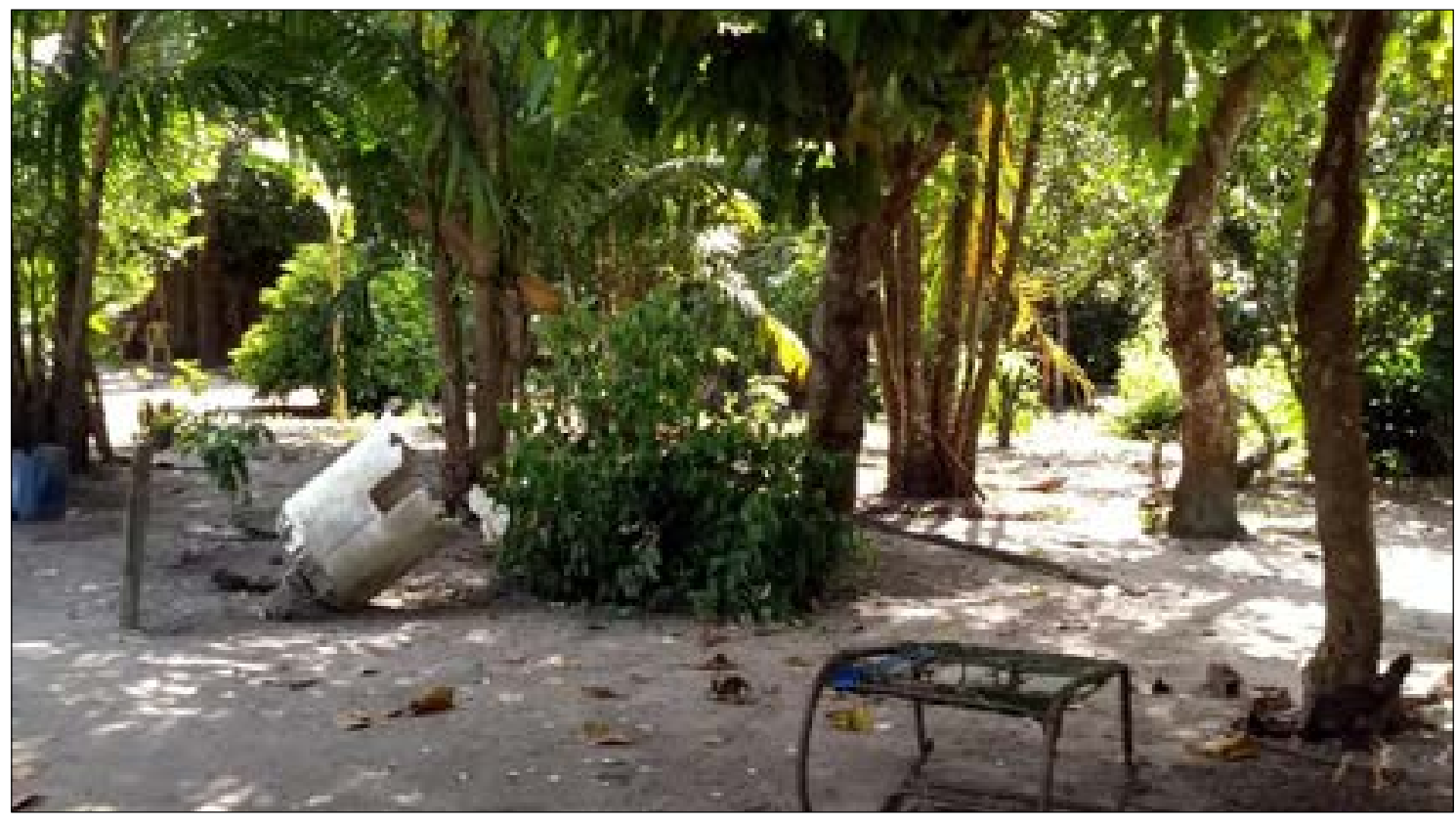

Figura 5 - Quintal de dona Socorro. Foto: Ana Célia Guedes (2017).

transmitir esse conhecimento para suas filhas. mãe ou avó, sendo que com saberes também Muitas delas sabem disso desde pequenas, pois se transmite experiências sociais e a sabedoria a criança aprende as primeiras tarefas com sua comum ao grupo social (Thompson 1998). 
Tabela 1 - Lista de algumas plantas medicinais usadas pelas pessoas da comunidade de Santa Rita de Barreira. Informações coletadas por Ana Célia Guedes, em trabalho de campo em Santa Rita de Barreira, no ano de 2017.

Fontes das referências científicas citadas: Cunningham (2008) e Wikipédia (2020).

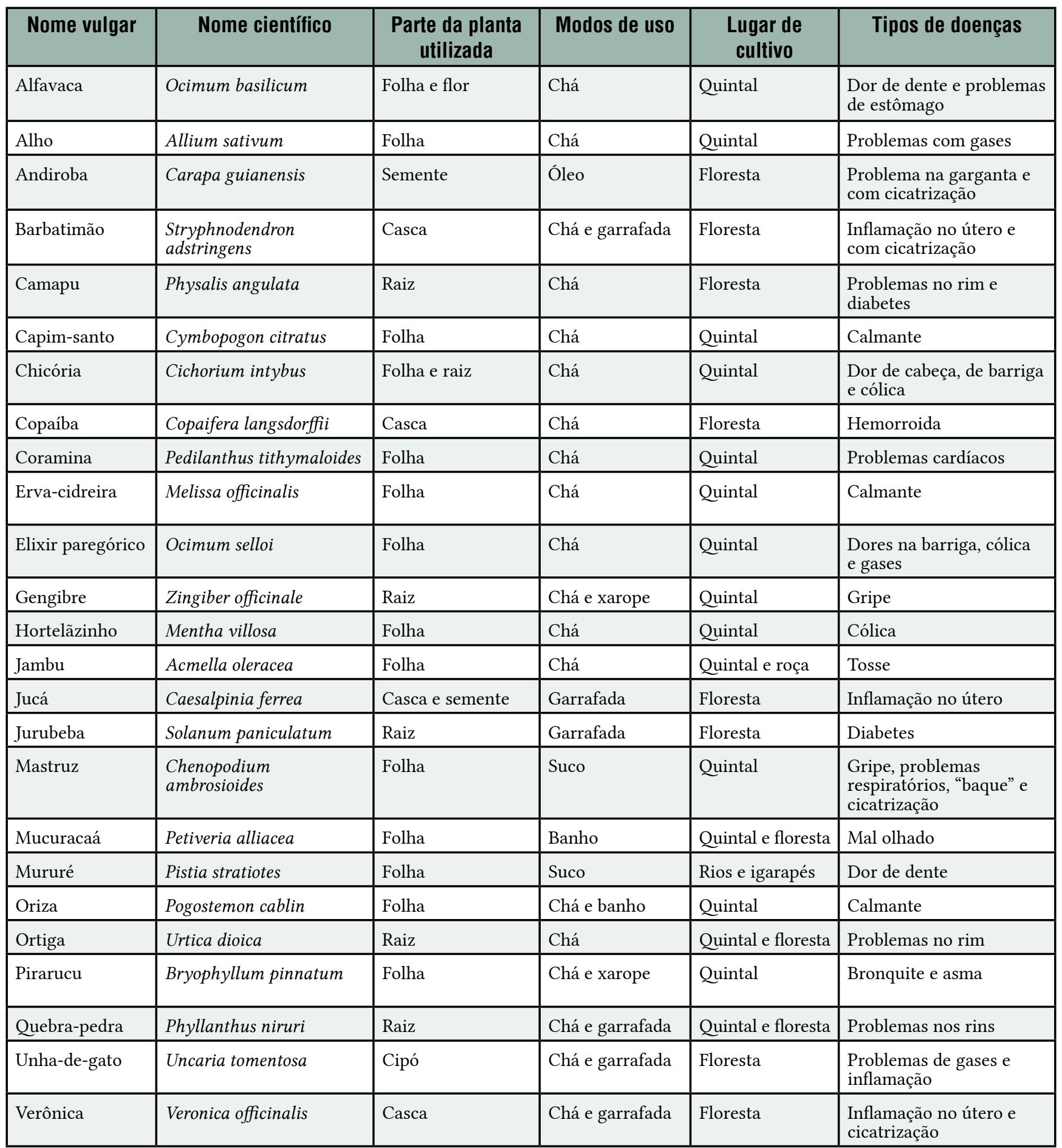


A partir da Tabela 1, é possível observar que as folhas e as raízes são as partes mais usadas pelas mulheres da comunidade estudada para tratar algumas doenças, assim como a maioria dos remédios usados é consumida por meio de chás. Grande parte dessas plantas é cultivada nos quintais das mulheres, outras estão na floresta e um número pequeno é encontrado em rios e igarapés. A Tabela 1 sugere que algumas doenças podem ser tratadas ou curadas com mais de uma espécie de planta, assim como as partes de uma mesma espécie podem ser usadas para prevenção, tratamento ou cura de diferentes enfermidades. Durante a pesquisa de campo, as mulheres da comunidade relataram que utilizam as plantas medicinais cultivadas nos quintais, coletadas na floresta, no rio ou nos igarapés para tratar de mais de 20 (vinte) tipos de doenças. Para tanto, elas usam a flor, a folha, a raiz, a casca, entre outras partes, para fazer chás, xaropes ou garrafadas.

Desde o período colonial, no Brasil, as mulheres e suas doenças viviam em um território de saberes que eram transmitidos oralmente por gerações, e o mundo vegetal estava cheio de símbolos e práticas ligadas ao quintal, à horta e às plantas, como bem destacou Del Priore (2013).

Nesse sentido, a natureza tem sido fornecedora de recursos que acabaram servindo para a prevenção e o combate de males do corpo. Por isso, os povos de Santa
Rita de Barreira procuram usar a matéria-prima da floresta visando à resiliência do ecossistema da região.

O manejo e a manipulação de plantas medicinais praticados pelas mulheres da comunidade são marcados pelo direito de usufruto desse recurso por todos os que residem no território quilombola ou mesmo em territórios vizinhos. Porém, todos devem obedecer às regras que são aceitas e seguidas pelas práticas sociais estabelecidas pelo grupo ao longo dos anos.

Para Packer (2015), o manejo dos recursos naturais feito pelo sistema de uso comum por várias gerações gera normas baseadas nos costumes e não nas leis ditadas pelo Estado. Tais normas regulam os conhecimentos e as formas coletivas de trabalho relacionadas à biodiversidade e à produção de alimentos. Desse modo, as regras que são aceitas por esses povos são os acordos coletivos, orais ou escritos que regulam a gestão de uso coletivo dos recursos naturais existentes no território.

Os moradores da comunidade vêm lutando ao longo dos anos pela sua subsistência, investindo no cultivo de várias espécies de plantas, que servem como alimento e como medicamentos. Além disso, batalham pela transmissão dos saberes e do simbolismo relacionados ao cultivo e à manipulação de plantas para fins medicinais, bem como pela conservação da floresta, na qual estão muitas espécies utilizadas no tratamento dos enfermos. 
Para tanto, a maior parte das mulheres da comunidade ergue, em seus quintais, onde cultivam várias espécies de plantas, pequenas cercas, que servem para impedir o acesso de animais existentes no local. Durante os períodos de pouca chuva, as mulheres regam as plantas todos os dias, para que não venham a morrer. Esses cuidados, porém, não são feitos com vistas à comercialização desses recursos, e sim buscam a conservação das espécies, já que sabem que podem precisar delas para tratar as possíveis enfermidades que possam acometer seus parentes, vizinhos e amigos.

\section{CONSIDERAÇÕES FINAIS}

Ao analisar o uso da medicina popular e as dinâmicas culturais no cotidiano das moradoras da comunidade quilombola de Santa Rita de Barreira, é possível depreender como o uso terapêutico de plantas faz parte do tratamento de doenças, tais como diabetes, inflamação no útero, cólicas, gases, dor de barriga, vermes, asma, entre outras. Isso ocorre devido à herança cultural indígena e africana presente nas relações culturais desse grupo social, pois várias mulheres dessa comunidade, mesmo tendo acesso ao sistema de saúde, mantêm as práticas e os sistemas de curas a partir do uso terapêutico de plantas; outras usam as duas medicinas simultaneamente.

A vivência na e da floresta levou esses povos a buscarem diversas maneiras de conservação dos recursos naturais existentes na região, plantando algumas árvores em seus quintais, para tratamento de doenças, por meio de chás, banhos ou garrafadas, para serem usados como alimentos, a exemplo de mangueira, laranjeira etc., ou, ainda, para conservar a floresta em pé, pois ali há vários recursos naturais que são diariamente coletados pelos membros da comunidade.

Em face disso, destaca-se a necessidade de se considerar os povos quilombolas, existentes na Amazônia brasileira, em especial os de Santa Rita de Barreira, como aqueles que apresentam um modo de vida próprio, que se diferencia bastante do modelo eurocêntrico imposto pelo colonizador e depois pelos projetos de nação dos diferentes dirigentes do Estado brasileiro. Tal necessidade está ligada, nesse sentido, ao reconhecimento da diversidade de povos e culturas existentes no país, a qual define os ritmos de vida e a alteridade dos grupos sociais existentes na Amazônia Legal. Isso implica políticas públicas de proteção a estes saberes e conhecimentos tradicionais, bem como possibilidade de condições para que eles permaneçam sendo praticados e vivenciados. No entanto, o avanço de extração descontrolada dos recursos naturais por terceiros nestes territórios é uma séria ameaça à mata/floresta local, onde são extraídas as plantas de tratamento e/ou cura, e consequentemente à reprodução dos saberes tradicionais e do modo de vida da comunidade quilombola. 


\section{REFERÊNCIAS}

Alberti, V. 2010. História dentro da História, in: Fontes históricas. Organizado por C. B. Pinsky, pp. 155-202. São Paulo: Contexto.

Araújo, A. W. 1979. Medicina rústica. São Paulo: Cia Ed. Nacional.

Coelho-Ferreira, M. R., e M. A. G. Jardim. 2005. Algumas espécies vegetais usadas pelos moradores da Ilha de Algodoal, Maiandeua, município de Maracanã, Pará. Boletim do Museu Paraense Emílio Goeldi. Série Ciências Naturais 1(2):45-51.

Creswell, J. W. 2007. Projeto de pesquisa: métodos qualitativo, quantitativo e misto. Porto Alegre: Artmed.

Cunningham, S. 2008. Cunningham's encyclopedia of magical herbs. 2. ed. Woodbury: Llewellyn Publications.

Del Priore, M. (Org.). 2013. História das mulheres no Brasil. 2. ed. São Paulo: Contexto.

Diniz, R. E. S. 2011. Territorialidade e uso comum entre os quilombolas de Santa Rita da Barreira em contradição com "políticas de etnodesenvolvimento”. Dissertação de Mestrado, Núcleo de Altos Estudos Amazônicos, Universidade Federal do Pará, Brasil.

Eichemberg, M. T., M. C. M. Amorozo, e L. C. Moura. 2009. Species composition and plant use in old urban homegardens. Southeast of Brazil. Acta Botanica Brasilica 23(4):1057-1075. DOI: http://dx.doi. org/10.1590/S0102-33062009000400016

Federici, S. 2010. Calibã e as bruxas: mulheres, corpos e acumulação originária. São Paulo: Editora Elefante.

Freire, P. 2008. Gênero e saberes da Amazônia: reflexões sobre saúde e conhecimentos tradicionais. Seminário Internacional Fazendo Gênero. Corpo, Violência e Poder. Disponível em: http://www.wwc2017. eventos.dype.com.br/fg8/sts/ST19/Priscila_Freire_19.pdf. Acesso em: fev. 2018. 
Gaskell, G. 2008. Entrevistas individuais e grupais, in Pesquisa qualitativa com texto, imagem e som: um manual prático. Editado por M. W. Bauer e G. Gaskell, pp. 64-89. Rio de Janeiro: Vozes.

Gil, A. C. 1999. Métodos e técnicas de pesquisa social. São Paulo: Atlas.

Guedes, A. C. B. 2018. Mulheres quilombolas e uso de plantas medicinais: práticas de cura em Santa Rita de Barreira/PA. Dissertação de Mestrado, Núcleo de Altos Estudos Amazônicos, Universidade Federal do Pará, Brasil.

Lévi-Strauss, C. 1989. O pensamento selvagem. 8. ed. Campinas: Papirus.

Lozano, J. E. A. 2006. Práticas e estilos de pesquisa na história oral contemporânea, in Usos e abusos da História Oral. Organizado por J. Amado e M. M. Ferreira, pp. 15-27. São Paulo: Editora FVG.

Oliveira, E. R. 1985. O que é medicina popular. São Paulo: Brasiliense.

Pará. 1998. Lei n. ${ }^{\circ}$ 6.165, de 02 de dezembro de 1998. Dispõe sobre a Legitimação de Terras dos Remanescentes das Comunidades dos Quilombos e dá outras providências. Diário Oficial. Disponível em: https://www.sistemas.pa.gov.br/sisleis/legislacao/1353. Acesso em: fev. 2018.

Pará. 1999. Decreto $\mathrm{n}^{\circ}$ 261, de 22 de novembro de 2011. Institui a Política Estadual para as Comunidades Remanescentes de Quilombos no Estado do Pará e dá outras providências. Diário Oficial. Disponível em: https://www.sistemas.pa.gov.br/sisleis/legislacao/980. Acesso em: fev. 2018.

Packer, L. A. 2015. Novo código florestal \& pagamentos por serviços ambientais: regime proprietário sobre os bens comuns. Curitiba: Juruá.

Portelli, A. 2016. História oral como arte da escuta. São Paulo: Letras e Vozes. 
Rodrigues, S. F. 2010. Senhores da cura: negociações e conflitos no diversificado universo da cura no extremo norte do Brasil, 1889-1919. Histórica - Revista Eletrônica do Arquivo Público do Estado de São Paulo (44):1-8.

Silva, N. C. B., A. C. Delfino Regis, M. A. Esquibel, J. E. S. Santos, e M. Z. Almeida. 2012. Uso de plantas medicinais na comunidade quilombola da Barra II - Bahia, Brasil. Boletín Latinoamericano y del Caribe de Plantas Medicinales y Aromáticas 11(5):35-453.

Thompson, E. P. 1998. Costumes em comum: estudo sobre a cultura popular tradicional. São Paulo: Companhia das Letras.

Trotta, J., P. A. Messias, A. C. H. Pires, C. T. Hayashida, C. Camargo, e C. Futemma. 2012. Análise do conhecimento e uso popular de plantas de quintais urbanos no estado de São Paulo. Revista de Estudos Ambientais 14(3):17-34.

Wikipédia. 2020. Disponível em: https://pt.wikipedia.org/wiki/Wikip\%C3\%A9dia:P\%C3\%A1gina_ principal. Acesso em: fev. 2018.

Winklerprins, A., e P. S. S. Oliveira. 2010. Urban agriculture in Santarém, Pará, Brazil: diversity and circulation of cultivated plants in urban homegardens. Boletim do Museu Paraense Emílio Goeldi. Ciências Humanas 5(3):571-585. DOI: http://dx.doi.org/10.1590/S1981-81222010000300002

Yin, R. K. 2010. Planejamento e métodos. Porto Alegre: Brookman. 